\title{
Predictive role of hand-foot syndrome in patients receiving first-line capecitabine plus bevacizumab for HER2-negative metastatic breast cancer
}

Christoph Zielinski ${ }^{*},{ }^{1,2}$, Istvan Lang ${ }^{3}$, Semir Beslija ${ }^{4}, Z^{2}$ suzsanna Kahan ${ }^{5}$, Moshe J Inbar ${ }^{6}$, Salomon M Stemmer ${ }^{7}$, Rodica Anghel ${ }^{8}$, Damir Vrbanec ${ }^{9}$, Diethelm Messinger ${ }^{10}$ and Thomas Brodowicz ${ }^{1,2}$

${ }^{1}$ Clinical Division of Oncology, Department of Medicine I and Comprehensive Cancer Center, Medical University Vienna - General Hospital, Waehringer Guertel 18-20, A-1090 Vienna, Austria; ${ }^{2}$ Central European Cooperative Oncology Group (CECOG), Waehringer Guertel 18-20, A-1090 Vienna, Austria; ${ }^{3}$ National Institute of Oncology, Ráth György u. 7-9, H-1122 Budapest, Hungary; ${ }^{4}$ Institute of Oncology, Clinical Center, University of Sarajevo, Bolnicka 27, 71000 Sarajevo, Bosnia and Herzegovina; ${ }^{5}$ Department of Oncotherapy, University of Szeged, Korányi fasor 12, H-6720 Szeged, Hungary; ${ }^{6}$ Oncology Division, Tel Aviv Sourasky Medical Center, 6 Weizman Street, Tel Aviv 64239, Israel; ${ }^{7}$ Davidoff Center, Rabin Medical Center, Kaplan Street, Petah Tikva 49100, Israel; ${ }^{8}$ University of Medicine and Pharmacy Bucharest, Soseaua Fundeni, Nr 252, Sector 2, Bucharest 022328, Romania; ${ }^{9}$ Department of Medical Oncology, University Hospital Zagreb-Rebro, Medical University of Zagreb, Kispaticeva 12, 10000 Zagreb, Croatia and ${ }^{10}$ IST GmbH, Soldnerstrasse 1, 68219 Mannheim, Germany

Background: Correlations between development of hand-foot syndrome (HFS) and efficacy in patients receiving capecitabine (CAP)-containing therapy are reported in the literature. We explored the relationship between HFS and efficacy in patients receiving CAP plus bevacizumab (BEV) in the TURANDOT randomised phase III trial.

Methods: Patients with HER2-negative locally recurrent/metastatic breast cancer (LR/mBC) who had received no prior chemotherapy for $\mathrm{LR} / \mathrm{mBC}$ were randomised to BEV plus paclitaxel or BEV-CAP until disease progression or unacceptable toxicity. This analysis included patients randomised to BEV-CAP who received $\geqslant 1$ CAP dose. Potential associations between HFS and both overall survival (OS; primary end point) and progression-free survival (PFS; secondary end point) were explored using Cox proportional hazards analyses with HFS as a time-dependent covariate (to avoid overestimating the effect of HFS on efficacy). Landmark analyses were also performed.

Results: Among 277 patients treated with BEV-CAP, 154 (56\%) developed HFS. In multivariate analyses, risk of progression or death was reduced by $44 \%$ after the occurrence of HFS; risk of death was reduced by $56 \%$. The magnitude of effect on OS increased with increasing HFS grade. In patients developing HFS within the first 3 months, median PFS from the 3-month landmark was 10.0 months vs 6.2 months in patients without HFS. Two-year OS rates were $63 \%$ and $44 \%$, respectively.

Conclusions: This exploratory analysis indicates that HFS occurrence is a strong predictor of prolonged PFS and OS in patients receiving BEV-CAP for $L R / m B C$. Early appearance of HFS may help motivate patients to continue therapy.

*Correspondence: Professor C Zielinski; E-mail: christoph.zielinski@meduniwien.ac.at

Received 15 June 2015; revised 8 October 2015; accepted 11 November 2015; published online 10 December 2015

(c) 2016 Cancer Research UK. All rights reserved 0007 - 0920/16 
In four randomised phase III trials, the addition of bevacizumab (BEV) to first-line chemotherapy has been shown to significantly improve progression-free survival (PFS) and overall response rate (Miller et al, 2007; Miles et al, 2010, 2015; Robert et al, 2011), but no effect on overall survival (OS) has been detected. The randomised phase III TURANDOT trial by the Central European Cooperative Oncology Group compared first-line bevacizumab plus paclitaxel (BEV-PAC) vs bevacizumab plus capecitabine (BEV-CAP) in patients with HER2-negative locally recurrent or metastatic breast cancer (LR/mBC) (Lang et al, 2013). Results from the pre-specified interim analysis were inconclusive for the primary end point (non-inferior OS with BEV-CAP vs BEV-PAC), but demonstrated significantly superior PFS (secondary end point) with BEV-PAC vs BEV-CAP (hazard ratio (HR), 1.36 (95\% confidence interval (CI) 1.09-1.68); $P=0.0052$; median PFS 11.0 and 8.1 months, respectively).

Post hoc exploratory analyses suggested differing treatment effects on OS according to clinical risk factors (Brodowicz et al, 2014). In the subgroup of patients with low-risk hormone receptorpositive disease (defined as one or none of the following risk factors: disease-free interval $\leqslant 24$ months; visceral metastases; prior anthracycline and/or taxane; or $\geqslant 3$ metastatic organ sites), there was a nonsignificant trend in OS favouring BEV-CAP. In the absence of a predictive biomarker for efficacy of either CAP or $\mathrm{BEV}$, this risk factor index based on clinical characteristics may help in selecting patients for initial BEV-CAP therapy, balancing tolerability, patient preference, and efficacy. Several reports in the literature suggest that hand-foot syndrome (HFS) - a well-known side effect of CAP - may also be of interest in predicting the efficacy of CAP-containing therapy. An exploratory analysis of a small single-arm Japanese study suggested that HFS occurrence in CAP-treated patients may be associated with improved efficacy (Taguchi et al, 2010). Similar observations were reported from two retrospective studies, each including almost 100 patients receiving various CAP-containing regimens for metastatic breast cancer (mBC) (Kurt et al, 2006; Azuma et al, 2012). A relationship between HFS development and efficacy was also noted in the larger single-arm prospective MONICA trial evaluating first-line CAP monotherapy for mBC (Kaufmann et al, 2010). Median time to disease progression (TTP) was 9.4 months in patients developing HFS vs 4.7 months in those without $(P=0.0542)$; median OS was 22.9 and 14.2 months, respectively $(P=0.0209)$. HFS was an independent prognostic factor for TTP and OS in univariate and multivariate analyses. However, a major limitation of these analyses, as well as their retrospective nature, is the bias introduced by the association between treatment duration and likelihood of developing HFS. HFS is a cumulative toxicity with a reported median time to onset of almost 8 months in a meta-analysis of more than 4700 patients receiving CAP-based therapy for various tumour types (Roche, 2014). Patients whose disease is controlled with CAP tend to have longer treatment exposure and consequently an increased likelihood of developing HFS, whereas patients who die or experience progression very early are less likely to develop HFS. This is illustrated by the previously mentioned analysis of the TURANDOT trial according to a simple prognostic factor index (Brodowicz et al, 2014). In patients with low-risk hormone receptor-positive disease, who appeared to derive the greatest benefit from BEV-CAP, the incidence of grade 3 HFS was $28 \%$ compared with $14 \%$ in those with high-risk hormone receptor-positive disease and $12 \%$ in those with triplenegative breast cancer. Corresponding median durations of CAP exposure were $8.3,7.4$, and 5.7 months, respectively. Clearly, a simple comparison of PFS and OS curves between patients with and without HFS during study treatment is likely to lead to an overestimation of the effect of HFS on efficacy.

In the X-ACT trial in stage III colon cancer, post hoc exploratory retrospective analyses of HFS were less confounded by treatment duration because patients received a fixed 24-week course of adjuvant CAP therapy and the probability of an event (relapse or death) before HFS occurred was relatively low, and lower than in $\mathrm{LR} / \mathrm{mBC}$. Interestingly, these analyses also suggested a relationship between HFS and efficacy. Patients experiencing HFS during CAP treatment had numerically better disease-free survival and OS than those without HFS (Twelves et al, 2012).

To explore a potential correlation between HFS and efficacy in patients receiving first-line BEV-CAP for HER2-negative $\mathrm{LR} / \mathrm{mBC}$, we performed analyses of the patients randomised to BEV-CAP in the TURANDOT trial, assessing whether the occurrence of HFS constituted an on-treatment predictive marker for improved efficacy of BEV-CAP.

\section{PATIENTS AND METHODS}

In the open-label randomised phase III non-inferiority TURANDOT trial, patients with HER2-negative $\mathrm{LR} / \mathrm{mBC}$ who had received no prior chemotherapy for $\mathrm{LR} / \mathrm{mBC}$ were randomly assigned to receive either BEV-PAC (BEV $10 \mathrm{mg} \mathrm{kg}^{-1}$ on days 1 and 15 plus paclitaxel $90 \mathrm{mg} \mathrm{m}^{-2}$ on days 1,8 , and 15 , repeated every 4 weeks) or BEV-CAP (BEV $15 \mathrm{mg} \mathrm{kg}^{-1}$ on day 1 plus CAP $1000 \mathrm{mg} \mathrm{m}^{-2}$ twice daily on days $1-14$, repeated every 3 weeks). The primary end point in the TURANDOT trial was OS; PFS was a secondary end point. Sample size calculations and statistical methods for the trial have been reported previously (Lang et al, 2013). In the present analyses, only patients randomised to BEV-CAP who received at least one dose of CAP were included.

Adverse events were graded according to Common Terminology Criteria for Adverse Events (version 3.0) at every cycle throughout the study and for 28 days after treatment discontinuation. If patients experienced grade 2 or $3 \mathrm{HFS}$, CAP treatment was interrupted until HFS improved to grade 0 or 1 . Subsequent doses of CAP were decreased to $75 \%$ of the starting dose at the first occurrence of grade 2 or $3 \mathrm{HFS}$, and to $50 \%$ of the starting dose at the second occurrence. If patients experienced a third HFS episode, CAP was discontinued permanently. Vitamin B6 was permitted for symptomatic or secondary prophylactic treatment of HFS.

All patients provided written informed consent before study entry. The institutional review board of each participating institution approved the study protocol.

The association between HFS and OS or PFS was analysed using Cox proportional hazards adjusted for various baseline characteristics. Kaplan-Meier methods were used to visualise PFS and OS curves and estimate survival rates at various time points for patients with and without HFS. To avoid overestimating the effect of HFS on efficacy, as mentioned earlier, the primary analysis of the association between HFS and PFS or OS used Cox proportional hazard methods with HFS as a time-dependent covariate. In the first analysis, the occurrence of HFS irrespective of grade was considered as a time-dependent variable (level 1 for all days after the first HFS occurrence, level 0 for all days preceding the first occurrence and all days in patients without HFS). In the second analysis, HFS grade $(1,2$, or 3 vs no HFS) was considered as a timedependent variable. The highest grade was assumed for all days after the first occurrence of HFS, even if HFS subsequently improved or resolved completely. Stepwise selection procedures with significance levels of $P<0.1$ for entering and $P<0.05$ for staying in the model were used after preselection of covariates in a preceding univariate step (univariate $P<0.25$ ).

Additional Cox proportional hazards landmark analyses were used to investigate the impact of early HFS occurrence (during the first 3 months of treatment) on PFS and OS. The landmark was set at treatment day 91; patients with a PFS or OS event before the landmark were excluded from the corresponding analyses. Kaplan-Meier 
methods were used to visualise PFS and OS curves and estimate survival rates across time points. The advantage of the landmark analysis (similar to the Cox model with HFS as a time-dependent covariate) is that effects of HFS on PFS or OS are not overestimated; however, this approach ignores the effect of HFS on events before the landmark, unlike the time-dependent covariate in the Cox model.

\section{RESULTS}

The analysis population included 277 patients treated with BEV-CAP (Figure 1). HFS was the most common adverse event (56\% of patients overall), followed by hypertension (29\%) and fatigue (27\%). Among the 154 patients experiencing HFS, this event occurred at grade 1 in 54 patients (19\%), grade 2 in 55 patients (20\%), grade 3 in 44 patients (16\%), and at unknown grade in 1 patient. The remaining 123 patients (44\%) did not develop HFS during study treatment. Baseline characteristics were quite similar between patients with $v s$ without HFS (Table 1). The main differences were the higher proportions of patients in the non-HFS subgroup with lung metastases, $\geqslant 3$ metastatic organ sites, and hormone receptor-negative disease, and the lower proportion with prior endocrine therapy for $\mathrm{LR} / \mathrm{mBC}$ (consistent with the difference in hormone receptor status).

Table 2 summarises treatment exposure. The most common reason for discontinuing $\mathrm{BEV}$ and/or CAP in both subgroups was disease progression. In the HFS subgroup, disease progression led to BEV discontinuation in $62 \%$ of patients and CAP discontinuation in $60 \%$. Corresponding percentages in patients without HFS were $65 \%$ and $67 \%$, respectively. Adverse events leading to discontinuation of BEV were observed in $11 \%$ of patients who developed HFS and 20\% of those who did not experience HFS; for CAP discontinuation, the proportion was $19 \%$ in both subgroups.

The median duration of follow-up at the data cutoff for this analysis was 20.5 months (95\% CI 18.0-21.2 months) in patients developing HFS vs 18.0 months (95\% CI 16.1-18.7 months) in those without HFS. At this time PFS events had occurred in 214 patients (77\%) and 97 (35\%) had died. The most common cause of
Table 1. Baseline characteristics of patients randomised to bevacizumab plus capecitabine according to development or not of hand-foot syndrome

\begin{tabular}{|c|c|c|}
\hline \multirow[b]{2}{*}{ Characteristics } & \multicolumn{2}{|c|}{ No. of patients (\%) } \\
\hline & HFS $(n=154)$ & No HFS $(n=123)$ \\
\hline Median age, years (range) & $59(27-86)$ & $58(28-82)$ \\
\hline \multicolumn{3}{|l|}{ Menopausal status } \\
\hline $\begin{array}{l}\text { Pre-menopausal } \\
\text { Post-menopausal } \\
\text { Male }\end{array}$ & $\begin{array}{c}30(19.5) \\
121(78.6) \\
3(1.9)\end{array}$ & $\begin{aligned} 20 & (16.3) \\
102 & (82.9) \\
1 & (0.8)\end{aligned}$ \\
\hline \multicolumn{3}{|l|}{ ECOG performance status } \\
\hline $\begin{array}{l}0 \\
1 \\
2\end{array}$ & $\begin{array}{l}105(68.2) \\
47(30.5) \\
2(1.3)\end{array}$ & $\begin{array}{c}74(60.2) \\
44(35.8) \\
5(4.1)\end{array}$ \\
\hline \multicolumn{3}{|l|}{ Hormone receptor status } \\
\hline $\begin{array}{l}\text { ER and/or PgR positive } \\
\text { ER and PgR negative }\end{array}$ & $\begin{array}{l}124(80.5) \\
30(19.5)\end{array}$ & $\begin{array}{l}86(69.9) \\
37(30.1)\end{array}$ \\
\hline Metastatic at first diagnosis & $32(20.8)$ & $26(21.1)$ \\
\hline \multicolumn{3}{|l|}{ Disease-free interval } \\
\hline $\begin{array}{l}\leqslant 12 \text { months } \\
>12-\leqslant 24 \text { months } \\
>24 \text { months } \\
\text { No disease-free interval }{ }^{a}\end{array}$ & $\begin{array}{c}4(2.6) \\
19(12.3) \\
96(62.3) \\
35(22.7)\end{array}$ & $\begin{array}{c}6(4.9) \\
14(11.4) \\
75(61.0) \\
28(22.8)\end{array}$ \\
\hline \multicolumn{3}{|l|}{ Metastatic organ sites } \\
\hline $\begin{array}{l}\text { Visceral } \\
\text { Liver } \\
\text { Lung } \\
\text { Soft tissue and/or bone only }\end{array}$ & $\begin{array}{l}113(73.4) \\
71(46.1) \\
61(39.6) \\
15(9.7)\end{array}$ & $\begin{array}{l}89(72.4) \\
54(43.9) \\
61(49.6) \\
8(6.5)\end{array}$ \\
\hline$\geqslant 3$ metastatic organ sites & $63(40.9)$ & $60(48.8)$ \\
\hline $\begin{array}{l}\text { Prior endocrine therapy } \\
\text { For LR/mBC }\end{array}$ & $\begin{array}{l}105(68.2) \\
38(24.7)\end{array}$ & $\begin{array}{l}65(52.8) \\
19(15.4)\end{array}$ \\
\hline $\begin{array}{l}\text { Prior (neo)adjuvant } \\
\text { chemotherapy }\end{array}$ & $95(61.7)$ & $80(65.0)$ \\
\hline \multicolumn{3}{|c|}{$\begin{array}{l}\text { Abbreviations: } E C O G=\text { Eastern Cooperative Oncology Group; } E R=\text { oestrogen receptor; } \\
\mathrm{HFS}=\text { hand-foot syndrome; } \mathrm{LR} / \mathrm{mBC}=\text { locally recurrent/metastatic breast cancer; } \\
\mathrm{PgR}=\text { progesterone receptor. } \\
{ }^{\mathrm{a}} \text { Patient did not receive or did not respond to therapy for primary breast cancer. }\end{array}$} \\
\hline
\end{tabular}

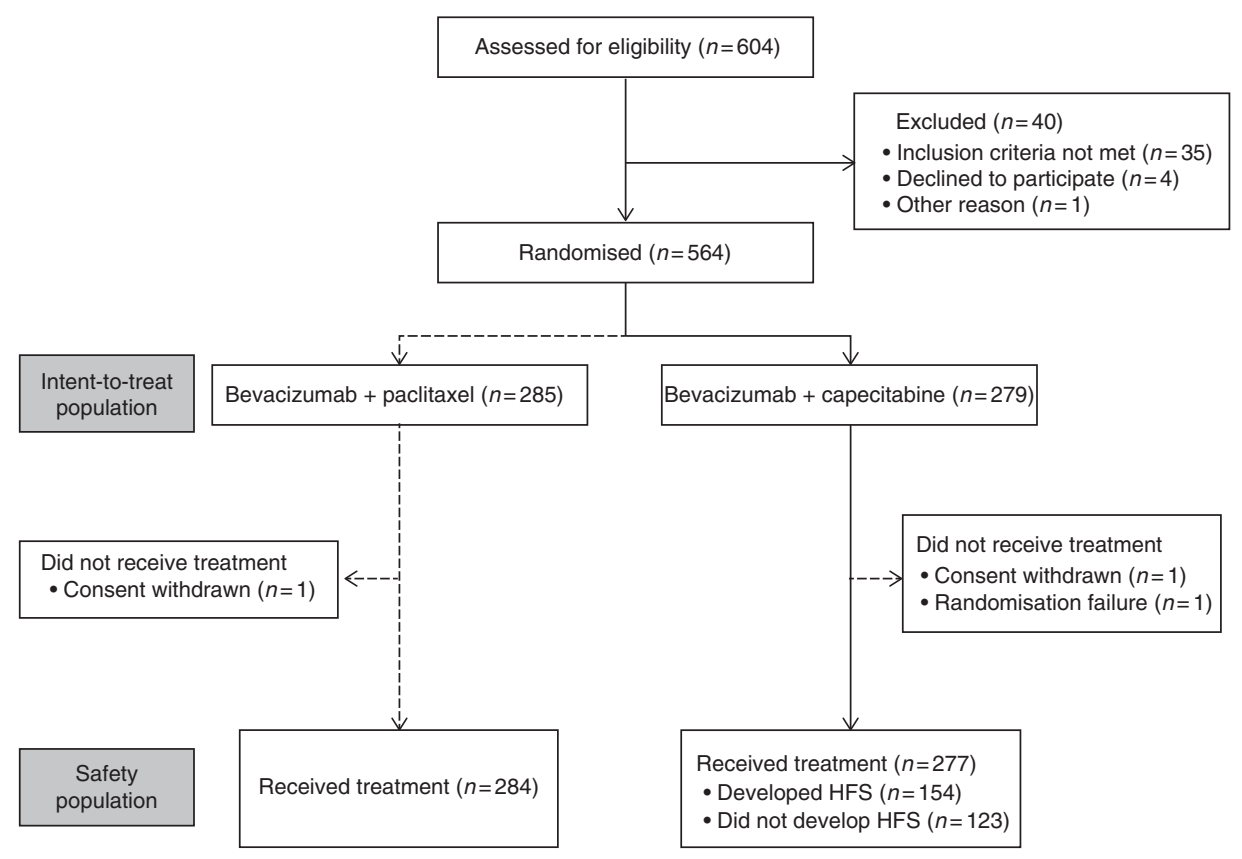

Figure 1. Patient flow. HFS=hand-foot syndrome. 
Table 2. Treatment exposure in patients randomised to bevacizumab plus capecitabine according to development or not of HFS

\begin{tabular}{|c|c|c|}
\hline $\begin{array}{l}\text { Treatment } \\
\text { exposure }\end{array}$ & $\operatorname{HFS}(n=154)$ & No HFS $(n=123)$ \\
\hline \multicolumn{3}{|c|}{ Still receiving study therapy at the time of data cut-off, $n(\%)$} \\
\hline Bevacizumab & $24(15.6)$ & $3(2.4)$ \\
\hline Capecitabine & $23(14.9)$ & $3(2.4)$ \\
\hline \multicolumn{3}{|c|}{ Mean cumulative dose (s.d.) } \\
\hline Bevacizumab, $\mathrm{mg} \mathrm{kg}^{-1}$ & $236.9(141.6)$ & $116.4(100.8)$ \\
\hline Capecitabine, $\mathrm{mg} \mathrm{m}^{-2}$ & $345878(194926)$ & $198233(166403)$ \\
\hline \multicolumn{3}{|c|}{ Median cumulative dose (range) } \\
\hline Bevacizumab, $\mathrm{mg} \mathrm{kg}^{-1}$ & $195.1(15.0-691.4)$ & $90.0(14.9-573.4)$ \\
\hline Capecitabine, $\mathrm{mg} \mathrm{m}^{-2}$ & 305202 (53 029-937 824) & $161204(4472-912818)$ \\
\hline \multicolumn{3}{|c|}{ Median treatment duration, months (range) } \\
\hline Bevacizumab & $8.9(<0.1-31.3)$ & $3.5(<0.1-29.2)$ \\
\hline Capecitabine & $9.2(1.1-31.7)$ & $4.5(0.1-26.0)$ \\
\hline \multicolumn{3}{|c|}{ Mean relative dose intensity, \% } \\
\hline Bevacizumab & 99 & 100 \\
\hline Capecitabine & 87 & 91 \\
\hline $\begin{array}{l}\text { Patients with an } \mathrm{AE} \\
\text { leading to } \\
\text { bevacizumab and/or } \\
\text { capecitabine } \\
\text { discontinuation, } n(\%)^{\text {a }}\end{array}$ & $36(23.4)$ & $29(23.6)$ \\
\hline $\begin{array}{l}\text { Bevacizumab and } \\
\text { capecitabine }\end{array}$ & $8(5.2)$ & $19(15.4)$ \\
\hline Bevacizumab & $17(11.0)$ & $25(20.3)$ \\
\hline Capecitabine & $30(19.5)$ & $23(18.7)$ \\
\hline $\begin{array}{l}\text { Patients with an } A E \\
\text { leading to capecitabine } \\
\text { modification, } n(\%)^{a}\end{array}$ & $106(68.8)$ & $41(33.3)$ \\
\hline Interruption & $25(16.2)$ & $7(5.7)$ \\
\hline Dose reduction & $52(33.8)$ & $10(8.1)$ \\
\hline Delay & $64(41.6)$ & $31(25.2)$ \\
\hline \multicolumn{3}{|c|}{ Patients with HFS leading to capecitabine adaptation, $n(\%)^{a}$} \\
\hline Discontinuation & $16(10.4)$ & 0 \\
\hline Dose modification & $71(46.1)$ & 0 \\
\hline
\end{tabular}

death in both subgroups was disease progression (32 of 37 patients (86\%) with HFS vs 49 of 60 patients (82\%) without HFS). Diseaserelated complications resulted in death in three patients in the HFS subgroup (all $>28$ days after discontinuing study treatment) and six patients in the non-HFS subgroup (four patients within 28 days of stopping study treatment and two patients $>28$ days after stopping study treatment). Figure 2 shows PFS and OS. Best overall response of complete or partial response was achieved in 38\% of patients with HFS $v s 14 \%$ of those without.

In univariate Cox proportional hazards analyses, HFS was strongly associated with improved PFS and OS in both the analysis irrespective of HFS grade and that taking into account HFS severity (Table 3). Other parameters associated with improved PFS and OS in univariate Cox proportional hazards analyses were Eastern Cooperative Oncology Group (ECOG) performance status 0, hormone receptor-positive disease, absence of lymph node metastases, absence of lung metastases (OS only), and sum of tumour diameters $\leqslant 5 \mathrm{~cm}$ (OS only). In a subsequent stepwise selection process with a significance level of $P<0.10$ to enter the model and $P<0.05$ to stay, all parameters with $P<0.25$ in the univariate analyses were considered. In the final models, occurrence of HFS and ECOG performance status 0 (and for OS only: hormone receptor-positive disease) remained significantly associated with improved PFS and OS. The same prognostic factors entered the final models with HFS grading.
Among patients developing HFS, the risk for progression or death was reduced by more than $40 \%$ (HR 0.56 in multivariate analysis; Table 3); the risk reduction exceeded $55 \%$ for OS (HR 0.44 in multivariate analysis). Further analyses according to HFS severity indicated that the degree of risk reduction for OS increased with increasing HFS grade (Table 3 ). For PFS, a slightly stronger risk reduction was observed with grade 2 than grade 1 HFS, but the risk reduction was not greater for grade $3 v s$ grade 2 .

In the landmark analyses, median PFS was 10.0 months after the 3-month landmark (95\% CI 6.2-13.4 months) in the 92 patients developing HFS within 3 months of starting study treatment vs 6.2 months (95\% CI 5.0-8.3 months) in the 123 patients without HFS by this time (two-sided log-rank $P=0.0026$; Figure $3 \mathrm{~A}$ ). The OS rates 2 years after the landmark were 63\% (95\% CI 50-74\%) in the 105 patients developing HFS within 3 months of starting treatment vs $44 \%$ (95\% CI $31-56 \%)$ in the remaining 159 patients (two-sided $\log$-rank $P=0.0842$; Figure $3 \mathrm{~B}$ ).

Analysis of post-study therapy, which potentially influences OS, showed slight differences according to the presence or absence of HFS. Specifically, more patients in the non-HFS than in the HFS subgroup received second-line chemotherapy (52 and 42\%, respectively) and/or taxane-based therapy (41 and 32\%, respectively) after discontinuing BEV-CAP (Table 4).

\section{DISCUSSION}

These exploratory subgroup analyses of the TURANDOT trial suggest that HFS is a strong predictor for prolonged PFS and OS in patients receiving first-line $\mathrm{BEV}-\mathrm{CAP}$ for HER2-negative $\mathrm{LR} / \mathrm{mBC}$. The risk of progression or death was approximately halved in patients developing HFS, and landmark analyses support the observed relationship between HFS and efficacy of BEV-CAP. The results of our post hoc analysis are consistent with other reports in the literature and with information in the CAP prescribing information (Roche, 2014). A meta-analysis of 14 clinical trials including more than 4700 patients treated with CAP (alone or combined with different chemotherapy regimens) in multiple indications (colon, colorectal, gastric, and breast cancers) showed that patients receiving CAP who developed HFS had longer OS than those without HFS (HR 0.61 (95\% CI $0.56-0.66)$; median OS 36.1 and 22.7 months, respectively) (Roche, 2014).

Comparison of the baseline characteristics suggests an imbalance in the two subgroups, with a potentially less favourable prognosis in patients who did not experience HFS in terms of number of metastatic organ sites, lung involvement, hormone receptor status, and prior endocrine therapy for advanced disease. However, the HFS effect estimated in the univariate Cox proportional model remained almost unchanged when adjusted for baseline characteristics that were significantly prognostic for PFS and OS.

The early occurrence of HFS may help physicians and patients to make a qualified decision about continuing CAP therapy. However, a practical limitation of the present analyses is that these data do not help in identifying which patients should start treatment with BEV-CAP rather than, for example, BEV-PAC, which was associated with superior PFS in the TURANDOT trial. Thymidine phosphorylase (TP), which has a critical role in the three-step enzymatic conversion of CAP to 5-fluorouracil at the tumour site, has attracted interest as a potential predictive marker for CAP efficacy. Several reports in the literature suggest that increased tumour TP concentrations may correlate with improved efficacy of CAP (Puglisi et al, 2008; Andreetta et al, 2009; Zhao et al, 2012; Bonotto et al, 2013). Interestingly, tumour samples from a small study in patients receiving CAP plus docetaxel for 

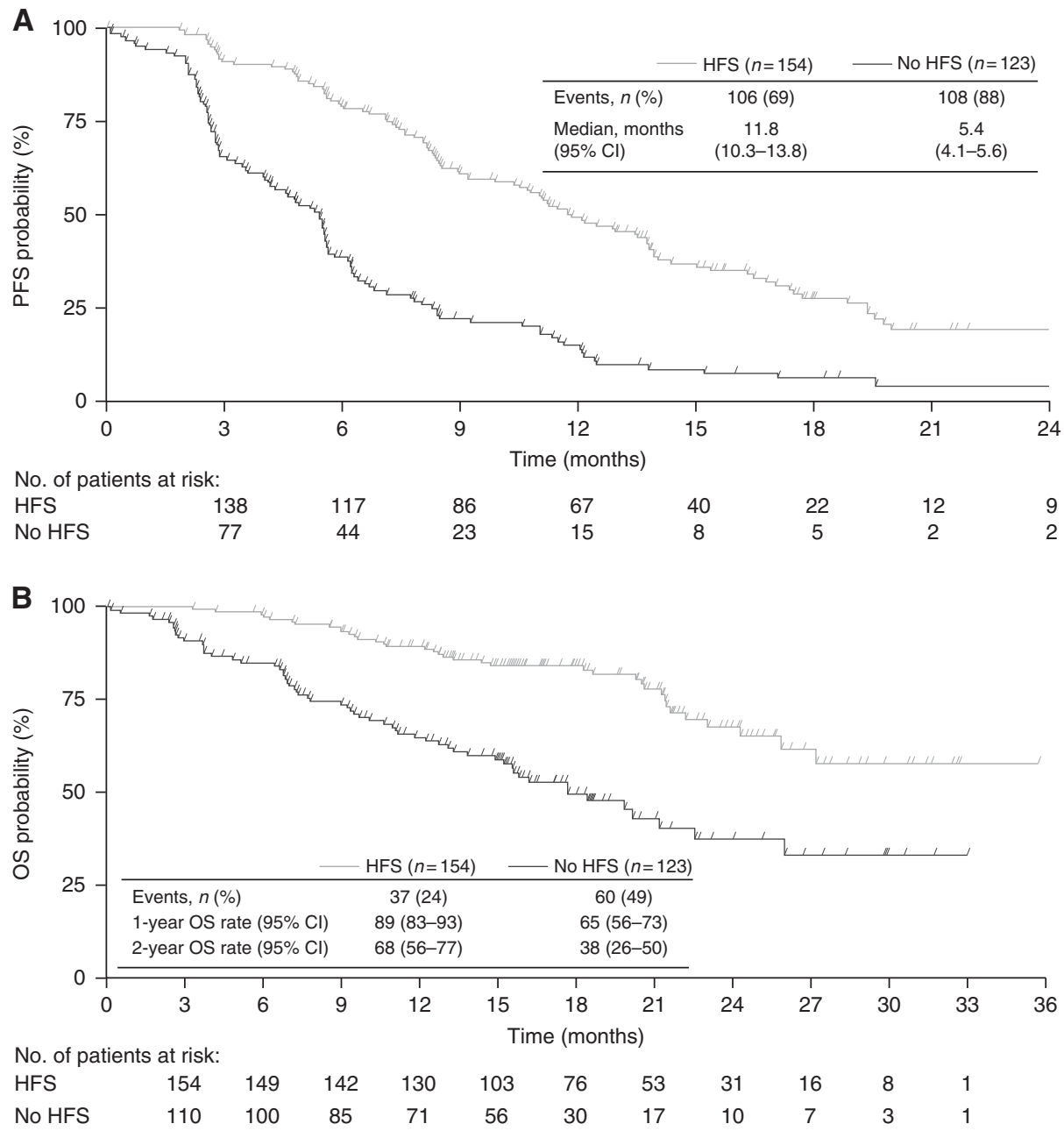

Figure 2. Efficacy according to the development of HFS in patients receiving bevacizumab plus capecitabine treatment. (A) PFS; (B) OS. $\mathrm{Cl}=$ confidence interval; $\mathrm{HFS}=$ hand-foot syndrome; OS=overall survival; PFS= progression-free survival.

Table 3. Cox proportional hazards models for PFS and OS with HFS as time-dependent covariate

\begin{tabular}{|c|c|c|c|c|c|}
\hline \multirow[b]{2}{*}{ End point } & \multirow[b]{2}{*}{ Time-dependent variable } & \multicolumn{2}{|c|}{ Univariate } & \multicolumn{2}{|c|}{ Multivariate $^{a}$} \\
\hline & & Hazard ratio $(95 \% \mathrm{Cl})$ & $P$-value & Hazard ratio $(95 \% \mathrm{Cl})$ & $P$-value \\
\hline PFS & $\begin{array}{c}\text { HFS (yes vs no) } \\
\text { Grade } 1 \text { HFS } \\
\text { Grade } 2 \text { HFS } \\
\text { Grade } 3 \text { HFS }\end{array}$ & $\begin{array}{l}0.577(0.431-0.772) \\
0.639(0.440-0.927) \\
0.481(0.321-0.720) \\
0.641(0.411-0.999)\end{array}$ & $\begin{array}{l}0.0002 \\
0.0184 \\
0.0004 \\
0.0495\end{array}$ & $\begin{array}{l}0.558(0.409-0.760) \\
0.536(0.350-0.821) \\
0.487(0.320-0.741) \\
0.740(0.466-1.178)\end{array}$ & $\begin{array}{l}0.0002 \\
0.0042 \\
0.0008 \\
0.2043\end{array}$ \\
\hline OS & $\begin{array}{l}\text { HFS (yes vs no) } \\
\text { Grade } 1 \text { HFS } \\
\text { Grade } 2 \text { HFS } \\
\text { Grade } 3 \text { HFS }\end{array}$ & $\begin{array}{l}0.417(0.273-0.637) \\
0.568(0.334-0.968) \\
0.417(0.227-0.765) \\
0.220(0.093-0.520)\end{array}$ & $\begin{array}{l}<0.0001 \\
0.0375 \\
0.0048 \\
0.0006\end{array}$ & $\begin{array}{l}0.436(0.285-0.666) \\
0.548(0.322-0.934) \\
0.448(0.243-0.824) \\
0.247(0.104-0.586)\end{array}$ & $\begin{array}{l}0.0001 \\
0.0270 \\
0.0098 \\
0.0015\end{array}$ \\
\hline \multicolumn{6}{|c|}{$\begin{array}{l}\text { Abbreviations: } \mathrm{Cl}=\text { confidence interval; HFS = hand-foot syndrome; OS = overall survival; PFS= progression-free survival. Grade } 1 \mathrm{HFS} \text { was defined as minimal skin changes or dermatitis (e.g., } \\
\text { erythema) without pain; grade } 2 \text { was defined as skin changes (e.g., peeling, blisters, bleeding, oedema) or pain, not interfering with function; and grade } 3 \text { was defined as ulcerative dermatitis or } \\
\text { skin changes with pain interfering with function. } \\
\left.{ }^{a} \text { Significant baseline factors in multivariate models: Eastern Cooperative Oncology Group performance status ( } 0 \text { vs } 1 / 2\right) \text { in all models; oestrogen receptor/progesterone receptor status (any } \\
\text { positive vs other) in both OS models. }\end{array}$} \\
\hline
\end{tabular}

non-small-cell lung cancer suggested that high tumour cell TP concentrations are associated with the development of HFS (Han et al, 2005). In patients receiving BEV-CAP combination therapy, TP may be of particular relevance because tumour cells overexpressing TP grow faster and form more angiogenic tumours (Jones et al, 2002). Furthermore, TP is commonly associated with the expression of other pro-angiogenic molecules, such as vascular endothelial growth factor - the target of BEV
(Toi et al, 1994; Bonotto et al, 2013). Indeed, HFS has been linked to the efficacy of another anti-angiogenic agent, sorafenib, in exploratory analyses in patients with hepatocellular and renal cell cancers (Cho et al, 2013; Nakano et al, 2013; Yada et al, 2014). Unfortunately there are no tumour tissue samples from TURANDOT, therefore we cannot explore whether the presence of HFS is a clinical marker of increased tumour TP concentration. However, this hypothesis is biologically plausible and merits 


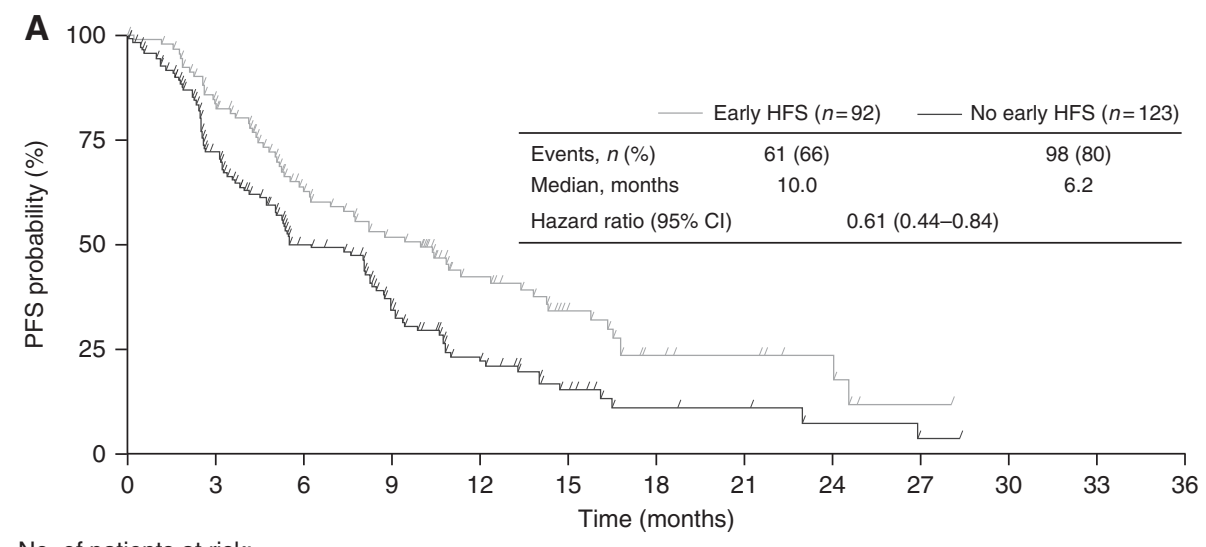

$\begin{array}{llllllllllll}\text { No. of patients at risk: } & & & & & & & \\ \text { Early HFS } & 74 & 52 & 43 & 28 & 16 & 9 & 7 & 3 & 1 & 0 & 0 \\ \text { No early HFS } & 87 & 57 & 37 & 20 & 11 & 5 & 4 & 2 & 1 & 0 & 0\end{array}$

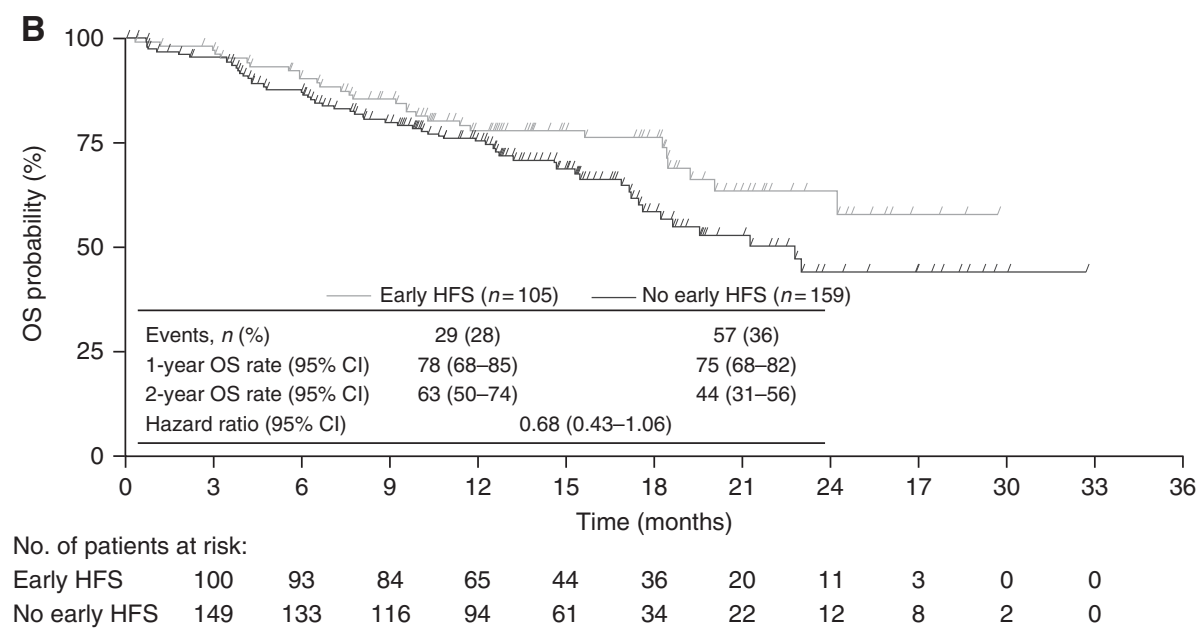

Figure 3. Landmark-analysis patients experiencing HFS within the first 3 months of bevacizumab plus capecitabine treatment compared with those who had not experienced HFS at this landmark. (A) PFS $(n=215)$; (B) OS $(n=264)$. Cl=confidence interval; HFS=hand-foot syndrome; OS=overall survival; PFS=progression-free survival.

Table 4. Post-study therapy in patients randomised to bevacizumab plus capecitabine according to development or not of HFS

\begin{tabular}{|l|c|c|}
\hline Treatment, $\boldsymbol{n}(\%)$ & HFS $(\boldsymbol{n}=\mathbf{1 5 4})$ & No HFS $(\boldsymbol{n}=\mathbf{1 2 3})$ \\
\hline Any therapy & $94(61.0)$ & $81(65.9)$ \\
Hormonal & $40(26.0)$ & $23(18.7)$ \\
Chemotherapy & $77(50.0)$ & $67(54.5)$ \\
Second line & $65(42.2)$ & $64(52.0)$ \\
Third line & $35(22.7)$ & $26(21.1)$ \\
Fourth line & $15(9.7)$ & $7(5.7)$ \\
Further line & $12(7.8)$ & $3(2.4)$ \\
Taxane & $49(31.8)$ & $50(40.7)$ \\
Bevacizumab & $9(5.8)$ & $5(4.1)$ \\
\hline Abbreviation: HFS = hand-foot syndrome.
\end{tabular}

further investigation, as a pretreatment predictor of efficacy is perhaps more clinically valuable than an on-treatment predictor of efficacy. Our study did not include pharmacokinetic evaluation, which would have enabled investigation of potential differences between patients with $v s$ without HFS.

In contrast to previous analyses reporting a potential predictive value of HFS with single-agent CAP for $\mathrm{LR} / \mathrm{mBC}$, patients in TURANDOT received BEV-CAP combination therapy. If CAP was discontinued because of HFS, patients could continue to receive $\mathrm{BEV}$ as a single agent. However, the approach taken by clinicians after discontinuing the administration of CAP may represent another potential imbalance: some may have considered that as patients could continue to receive BEV, they remained on active treatment, whereas others may have been reluctant to continue $\mathrm{BEV}$ alone based on the modest single-agent activity of $\mathrm{BEV}$ in $\mathrm{LR} / \mathrm{mBC}$, and may therefore have withdrawn patients from the study or switched them to another chemotherapy. Recently, results from the randomised phase III IMELDA trial provided new information on BEV-CAP maintenance therapy. In IMELDA, patients with a response or stable disease following initial BEV-taxane induction therapy were then randomised to maintenance therapy with BEV alone or BEV-CAP (Gligorov et al, 2014). BEV-CAP maintenance therapy was associated with statistically significant and clinically relevant improvements in the primary end point (PFS) and also OS (HR 0.43; $P=0.0003$; median OS 39.0 months with BEV-CAP vs 23.7 months with single-agent maintenance BEV). These findings strongly support switching to BEV-CAP after initial therapy; however, they do not directly inform on continuation of BEV-CAP in patients responding to initial treatment with this combination.

Reports in the literature have also suggested a potential correlation between hypertension and clinical outcome with antiangiogenic therapy in breast cancer and other tumour types (Schneider et al, 2008; Österlund et al, 2011; Evans, 2012). However, in a meta-analysis of individual patient data from almost 6500 patients treated in seven phase III trials of BEVcontaining therapy, including two trials in $\mathrm{LR} / \mathrm{mBC}$, early 
treatment-related hypertension was neither prognostic nor predictive for PFS and OS (Hurwitz et al, 2013). On the basis of these findings, as well as the relatively small number of patients developing hypertension, we did not perform post hoc analyses of hypertension in the TURANDOT trial to explore a potential correlation further.

The greater use of post-study taxane therapy in the non-HFS subgroup than in the HFS subgroup is interesting, and may suggest that investigators chose more intensive second-line chemotherapy for these patients with shorter PFS and OS. Similarly, the higher proportion of patients in the non-HFS subgroup who received second-line chemotherapy after discontinuing BEV-CAP may suggest more intensive treatment, balancing against a slightly higher proportion of patients receiving endocrine therapy in the HFS subgroup. These observations are consistent with clinical practice: if patients have prolonged disease control on BEV-CAP, physicians may switch to endocrine maintenance therapy, despite the lack of clinical evidence to support such a strategy. In contrast, for patients with rapid progression on BEV-CAP, physicians may select more intensive chemotherapy, such as a taxane-based regimen, to gain rapid disease control. This hypothesis is also consistent with the more aggressive baseline disease characteristics in the non-HFS subgroup. Alternatively, the greater prevalence of hormone receptor-negative disease among the non-HFS subgroup may explain the more frequent use of chemotherapy in these patients. The higher proportion of patients in the non-HFS group who had experienced a PFS event at the time of data cutoff may also contribute to the imbalance in second-line chemotherapy administration, as more patients in the non-HFS group had the opportunity to receive further lines of therapy. Finally, the greater attrition in later chemotherapy lines in the non-HFS subgroup is consistent with the shorter OS in these patients.

Practically, findings from these subgroup analyses may have important implications when treating patients with BEV-CAP. The development of HFS may help motivate patients to continue their oral therapy, while applying appropriate treatment interruptions and dose modifications to achieve an optimal tolerability/ efficacy balance. Early occurrence of HFS and its severity might help to guide treatment modifications and increase compliance with oral chemotherapy. Detection of biomarkers for HFS could strengthen this approach. The search for more individualised treatment and personalised health-care remains a high priority, while analyses such as our findings may help in monitoring and managing patients receiving BEV-CAP therapy for HER2-negative $\mathrm{LR} / \mathrm{mBC}$.

\section{ACKNOWLEDGEMENTS}

The TURANDOT trial was sponsored by the Central European Cooperative Oncology Group (CECOG) and supported financially by F. Hoffmann-La Roche Ltd.

Support for third-party writing assistance for this manuscript was provided by F. Hoffmann-La Roche Ltd., Basel, Switzerland.

\section{CONFLICT OF INTEREST}

CZ has received honoraria from and acted as a consultant for Roche; SB has received honoraria from and acted as a consultant for Roche, Pfizer, AbbVie, and Novartis; ZK has acted as a consultant for Roche; DV has received honoraria from Roche and Novartis and has acted as a consultant for Roche and Sanofi Aventis; DM is an employee of a contract research organisation that provides services to F. Hoffmann-La Roche; and TB has received honoraria from Amgen, Bayer, GSK, Eli Lilly, Merck, Novartis, PharmaMar, PrimeOncology, and Roche, and has acted as a consultant for Amgen, Bayer, Novartis, and PharmaMar. The remaining authors declare no conflict of interest.

\section{REFERENCES}

Andreetta C, Puppin C, Minisini A, Valent F, Pegolo E, Damante G, Di Loreto C, Pizzolitto S, Pandolfi M, Fasola G, Piga A, Puglisi F (2009) Thymidine phosphorylase expression and benefit from capecitabine in patients with advanced breast cancer. Ann Oncol 20: 265-271.

Azuma Y, Hata K, Sai K, Udagawa R, Hirakawa A, Tohkin M, Ryushima Y, Makino Y, Yokote N, Morikawa N, Fujiwara Y, Saito Y, Yamamoto H (2012) Significant association between hand-foot syndrome and efficacy of capecitabine in patients with metastatic breast cancer. Biol Pharm Bull 35: 717-724.

Bonotto M, Bozza C, Di Loreto C, Osa EO, Poletto E, Puglisi F (2013) Making capecitabine targeted therapy for breast cancer: which is the role of thymidine phosphorylase? Clin Breast Cancer 13: 167-172.

Brodowicz T, Lang I, Kahan Z, Greil R, Beslija S, Stemmer SM, Kaufman B, Petruzelka L, Eniu A, Anghel R, Koynov K, Vrbanec D, Pienkowski T, Melichar B, Spanik S, Ahlers S, Messinger D, Inbar MJ, Zielinski C (2014) Selecting first-line bevacizumab-containing therapy for advanced breast cancer: TURANDOT risk factor analyses. Br J Cancer 111: 2051-2057.

Cho JY, Paik YH, Lim HY, Kim YG, Lim HK, Min YW, Gwak GY, Choi MS, Lee JH, Koh KC, Paik SW, Yoo BC (2013) Clinical parameters predictive of outcomes in sorafenib-treated patients with advanced hepatocellular carcinoma. Liver Int 33: 950-957.

Evans T (2012) Utility of hypertension as a surrogate marker for efficacy of antiangiogenic therapy in NSCLC. Anticancer Res 32: 4629-4638.

Gligorov J, Doval D, Bines J, Alba E, Cortes P, Pierga JY, Gupta V, Costa R, Srock S, de Ducla S, Freudensprung U, Mustacchi G (2014) Maintenance capecitabine and bevacizumab versus bevacizumab alone after initial firstline bevacizumab and docetaxel for patients with HER2-negative metastatic breast cancer (IMELDA): a randomised, open-label, phase 3 trial. Lancet Oncol 15: 1351-1360.

Han JY, Hong EK, Lee SY, Yoon SM, Lee DH, Lee JS (2005) Thymidine phosphorylase expression in tumour cells and tumour response to capecitabine plus docetaxel chemotherapy in non-small cell lung cancer. J Clin Pathol 58: 650-654.

Hurwitz HI, Douglas PS, Middleton JP, Sledge GW, Johnson DH, Reardon DA, Chen D, Rosen O (2013) Analysis of early hypertension and clinical outcome with bevacizumab: results from seven phase III studies. Oncologist 18: $273-280$.

Jones A, Fujiyama C, Turner K, Cranston D, Williams K, Stratford I, Bicknell R, Harris AL (2002) Role of thymidine phosphorylase in an in vitro model of human bladder cancer invasion. J Urol 167: 1482-1486.

Kaufmann M, Maass N, Costa SD, Schneeweiss A, Loibl S, Sütterlin MW, Schrader I, Gerber B, Bauer W, Wiest W, Tomé O, Distelrath A, Hagen V, Kleine-Tebbe A, Ruckhaeberle E, Mehta K, von Minckwitz G. GBG-39 Trialists (2010) First-line therapy with moderate dose capecitabine in metastatic breast cancer is safe and active: results of the MONICA trial. Eur J Cancer 46: 3184-3191.

Kurt M, Aksoy S, Guler N (2006) Could the hand-foot syndrome after capecitabine treatment be associated with better outcome in metastatic breast cancer patients? Acta Oncol 45: 625-626.

Lang I, Brodowicz T, Ryvo L, Kahan Z, Greil R, Beslija S, Stemmer SM, Kaufman B, Zvirbule Z, Steger GG, Melichar B, Pienkowski T, Sirbu D, Messinger D, Zielinski C. Central European Cooperative Oncology Group (2013) Bevacizumab plus paclitaxel versus bevacizumab plus capecitabine as first-line treatment for HER2-negative metastatic breast cancer: interim efficacy results of the randomised, open label, non-inferiority, phase 3 TURANDOT trial. Lancet Oncol 14: 125-133.

Miles DW, Chan A, Dirix LY, Cortés J, Pivot X, Tomczak P, Delozier T, Sohn JH, Provencher L, Puglisi F, Harbeck N, Steger GG, Schneeweiss A, Wardley AM, Chlistalla A, Romieu G (2010) Phase III study of bevacizumab plus docetaxel compared with placebo plus docetaxel for the first-line treatment of human epidermal growth factor receptor 2-negative metastatic breast cancer. J Clin Oncol 28: 3239-3247.

Miles D, Cameron D, Bondarenko I, Manzyuk L, Carlos Alcedo J, Lopez RI, Im S-A, Canon J-L, Shparyk Y, Yardley D, Masuda N, Ro J, Denduluri N, Hubeaux S, Quah C, Bais C, O'Shaughnessy J (2015) First results from the 
double-blind placebo (PL)-controlled randomised phase III MERiDiAN trial prospectively evaluating plasma (p)VEGF-A in patients (pts) receiving first-line paclitaxel (PAC) \pm bevacizumab (BV) for HER2negative metastatic breast cancer (mBC). Eur J Cancer 51(Suppl 3): S287 (Abstract 1866).

Miller K, Wang M, Gralow J, Dickler M, Cobleigh M, Perez EA, Shenkier T, Cella D, Davidson NE (2007) Paclitaxel plus bevacizumab versus paclitaxel alone for metastatic breast cancer. $N$ Engl J Med 357: 2666-2676.

Nakano K, Komatsu K, Kubo T, Natsui S, Nukui A, Kurokawa S, Kobayashi M, Morita T (2013) Hand-foot skin reaction is associated with the clinical outcome in patients with metastatic renal cell carcinoma treated with sorafenib. Jpn J Clin Oncol 43: 1023-1029.

Österlund P, Soveri LM, Isoniemi H, Poussa T, Alanko T, Bono P (2011) Hypertension and overall survival in metastatic colorectal cancer patients treated with bevacizumab-containing chemotherapy. $\mathrm{Br} J$ Cancer 104: 599-604.

Puglisi F, Cardellino GG, Crivellari D, Di Loreto C, Magri MD, Minisini AM, Mansutti M, Andreetta C, Russo S, Lombardi D, Perin T, Damante G, Veronesi A (2008) Thymidine phosphorylase expression is associated with time to progression in patients receiving low-dose, docetaxel-modulated capecitabine for metastatic breast cancer. Ann Oncol 19: 1541-1546.

Robert NJ, Diéras V, Glaspy J, Brufsky AM, Bondarenko I, Lipatov ON, Perez EA, Yardley DA, Chan SY, Zhou X, Phan SC, O'Shaughnessy J (2011) RIBBON-1: randomized, double-blind, placebo-controlled, phase III trial of chemotherapy with or without bevacizumab for first-line treatment of human epidermal growth factor receptor 2-negative, locally recurrent or metastatic breast cancer. J Clin Oncol 29: 1252-1260.

Roche (2014) Xeloda summary of product characteristics http:// www.ema.europa.eu/docs/en_GB/document_library/EPAR__Product_Information/human/000316/WC500058151.pdf.

Schneider BP, Wang M, Radovich M, Sledge GW, Badve S, Thor A, Flockhart DA, Hancock B, Davidson N, Gralow J, Dickler M, Perez EA, Cobleigh M, Shenkier T, Edgerton S, Miller KD. ECOG 2100 (2008) Association of vascular endothelial growth factor and vascular endothelial growth factor receptor-2 genetic polymorphisms with outcome in a trial of paclitaxel compared with paclitaxel plus bevacizumab in advanced breast cancer: ECOG 2100. J Clin Oncol 26: 4672-4678.

Taguchi T, Nakayama T, Masuda N, Yoshidome K, Akagi K, Nishida Y, Yoshikawa Y, Ogino N, Abe C, Sakamoto J, Noguchi S. Kinki Breast Cancer Study Group (2010) Study of low-dose capecitabine monotherapy for metastatic breast cancer. Chemotherapy 56: 166-170.

Toi M, Hoshina S, Takayanagi T, Tominaga T (1994) Association of vascular endothelial growth factor expression with tumor angiogenesis and with early relapse in primary breast cancer. Jpn J Cancer Res $\mathbf{8 5}$ : 1045-1049.

Twelves C, Scheithauer W, McKendrick J, Seitz JF, Van Hazel G, Wong A, Díaz-Rubio E, Gilberg F, Cassidy J (2012) Capecitabine versus 5-fluorouracil/folinic acid as adjuvant therapy for stage III colon cancer: final results from the X-ACT trial with analysis by age and preliminary evidence of a pharmacodynamic marker of efficacy. Ann Oncol 23: 1190-1197.

Yada M, Masumoto A, Motomura K, Tajiri H, Morita Y, Suzuki H, Senju T, Koyanagi T (2014) Indicators of sorafenib efficacy in patients with advanced hepatocellular carcinoma. World J Gastroenterol 20: 12581-12587.

Zhao HY, Huang H, Hu ZH, Huang Y, Lin SX, Tian Y, Lin TY (2012) Evaluations of biomarkers associated with sensitivity to 5-fluorouracil and taxanes for recurrent/advanced breast cancer patients treated with capecitabine-based first-line chemotherapy. Anticancer Drugs 23: 534-542.

This work is published under the standard license to publish agreement. After 12 months the work will become freely available and the license terms will switch to a Creative Commons AttributionNonCommercial-Share Alike 4.0 Unported License. 